
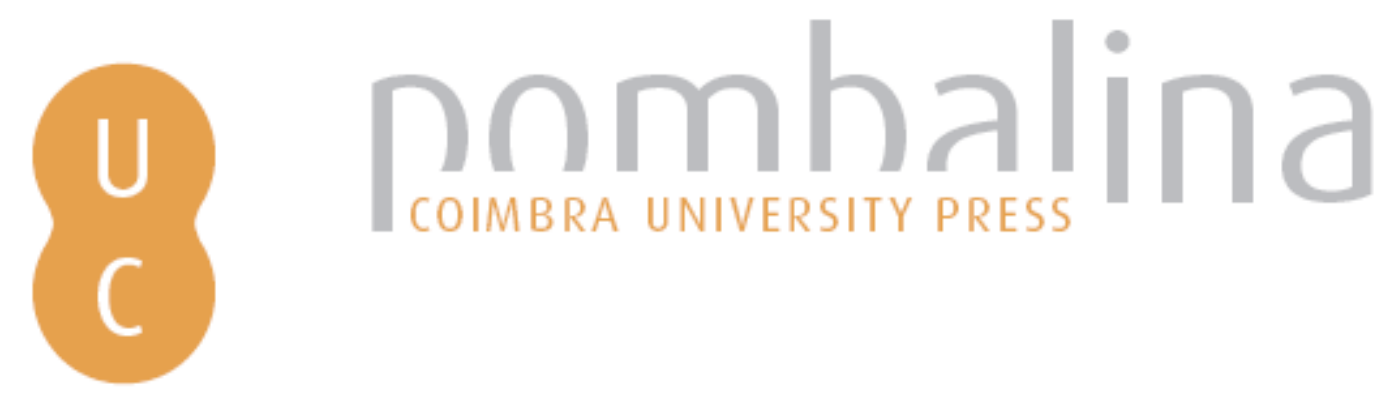

\title{
Microestrutura de minerais de ferro típicos de itabiritos anfibolíticos alterados do quadrilátero ferrífero (Brasil)
}
Autor(es):
Rocha, J. M. P.; Brandão, P. R. G.; Cançado, R. Z. L.
Publicado por: Imprensa da Universidade de Coimbra
URL
persistente:
URI:http://hdl.handle.net/10316.2/31453
DOI:
DOI:http://dx.doi.org/10.14195/978-989-26-0534-0_32
Accessed : $\quad$ 26-Apr-2023 01:41:51

A navegação consulta e descarregamento dos títulos inseridos nas Bibliotecas Digitais UC Digitalis, UC Pombalina e UC Impactum, pressupõem a aceitação plena e sem reservas dos Termos e Condições de Uso destas Bibliotecas Digitais, disponíveis em https://digitalis.uc.pt/pt-pt/termos.

Conforme exposto nos referidos Termos e Condições de Uso, o descarregamento de títulos de acesso restrito requer uma licença válida de autorização devendo o utilizador aceder ao(s) documento(s) a partir de um endereço de IP da instituição detentora da supramencionada licença.

Ao utilizador é apenas permitido o descarregamento para uso pessoal, pelo que o emprego do(s) título(s) descarregado(s) para outro fim, designadamente comercial, carece de autorização do respetivo autor ou editor da obra.

Na medida em que todas as obras da UC Digitalis se encontram protegidas pelo Código do Direito de Autor e Direitos Conexos e demais legislação aplicável, toda a cópia, parcial ou total, deste documento, nos casos em que é legalmente admitida, deverá conter ou fazer-se acompanhar por este aviso.

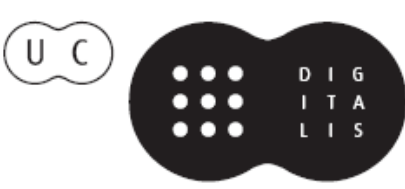





\title{
MICROESTRUTURA DE MINERAIS DE FERRO TÍPICOS DE ITABIRITOS ANFIBOLÍTICOS ALTERADOS DO QUADRILÁTERO FERRÍFERO (BRASIL)
}

\author{
MICROSTRUCTURE OF TYPICAL IRON MINERALS \\ PRESENT IN ALTERED AMPHIBOLITIC ITABIRITES \\ OF THE QUADRILÁTERO FERRÍFERO (BRAZIL)
}

\begin{abstract}
Resumo - A geometalurgia é utilizada para melhorar o entendimento de qualquer depósito mineral. A Samarco Mineraçáo S.A., um dos grandes produtores mundiais de pelotas de minério de ferro, investe em estudos de caracterização mineralógica dos minérios, como sustentação dos modelos geometalúrgicos de suas jazidas. Neste trabalho, propõe-se fazer uma investigação de detalhe na microestrutura de tipos de goethita que são muito comuns nos itabiritos de Alegria e apresentam forte influência no comportamento dos minérios que as contêm em abundância. Prepararam-se duas seçôes polidas de material moído e deslamado de amostras da tipologia itabirito anfibolítico martítico, para análises em microscópio óptico e eletrônico de varredura (MEV-EDS e MEV-FEG). Os principais minerais de ferro encontrados foram a martita (com ou sem magnetita relícta e goethita intra grão) e a goethita (botrioidal, pseudomórfica de anfibólio, terrosa e maciça). A porosidade e alteração dos minerais variam de médio a alto, o que é coerente com o ambiente e processo de geração desses minérios (enriquecimento supergênico). As feições texturais, treliça e esqueletal, observadas nas martitas destas amostras são típicas desse mineral nos minérios de Alegria. A hematita lamelar, de textura lisa e pouca porosidade, é totalmente distinta da martita, inclusive em seu comportamento perante processos de beneficiamento. A goethita, quando maciça, tem textura e forma totalmente distinta de quando está botrioidal ou substituindo de forma pseudomórfica o anfibólio anterior. As diferenças de forma e textura dos minerais são dos maiores responsáveis por um comportamento distinto dos minérios em processos de beneficiamento.
\end{abstract}

1 Samarco Mineração S.A., Mariana, MG, Brasil; junia@samarco.com

2 Depto. Engenharia de Minas, Univ. Federal Minas Gerais UFMG, Belo Horizonte, MG, Brasil; pbrandao@demin.ufmg.br 
Palavras-chave - Geometalurgia; Caracterização; Goethita; Itabirito anfibolítico

Abstract-Geometallurgy is applied to improve the understanding of any mineral deposit. Samarco Mineração S.A., one of the greatest worldwide iron ore pellets producer, invests on ore mineralogical characterization studies as a base for the geometallurgical models of its ore resources. The purpose of this work is to investigate in detail the microstucture of different types of goethite, which are regular in the itabirites of Alegria and have a strong influence on the behaviour of the ores that present them in abundance. Two polished sections were prepared from grinded and deslimed samples of the amphibolitic martitic tipology and were analyzed under optical and scanning electron (SEM-EDS e SEM-FEG) microscopes. The main iron minerals found were the martite (with or without relict magnetite and intra grain goethite) and goethite (botryoidal, pseudomorphic replacement of the amphibole, earthy e massive). The minerals porosity and alteration varies both from medium to high, which is consistent with the environment and generation process of the ores (supergenic enrichment). The martite fence framework and skeletal textures are typical of this mineral in the ores of Alegria. The lamellar hematite, with flat texture and lower porosity, is totally distinct from the martite including its beneficiation behaviour. The goethite, when massive, presents texture and form totally different of that when it is botryoidal or pseudomorphic after the previous amphibole. This form and texture minerals differences are the major responsible for the distinct behaviour of the ores in beneficiation and agglomeration processes.

\section{Keywords - Geometallurgy; Characterization; Goethite; Amphibolitic itabirite}

\section{1 - Introduçáo}

É do conhecimento comum, que o minério de ferro é um material policristalino que foi submetido a vários processos complexos naturais durante o tempo geológico devido aos efeitos dos diferentes gradientes, tais como, transformaçôes a alta e baixa pressão e temperaturas, calcinação, recristalização e intemperismo (VIEIRA et al., 2009). Esta história geológica leva-os a ter diferentes composições mineralógicas, texturais, granulométricas e estruturais, o que consequentemente conferem aos mesmos, diferentes comportamentos industriais (VAN VLACK, 1984).

$\mathrm{Na}$ indústria do ferro, a geometalurgia representa uma abordagem conceitual relativamente nova para o minério. Essa abordagem é utilizada para melhorar o entendimento do depósito mineral e classificar os diferentes tipos de minério, caracterizando sua variabilidade, entendendo sua qualidade intrínseca, realizando a identificação dos processos mais adequados para seu beneficiamento e aglomeração e, assim, maximizando seu valor presente, minimizando riscos e reduzindo a variabilidade dos resultados industriais (VIEIRA et al., 2009).

A Samarco Mineraçáo S.A., um dos grandes produtores mundiais de pelotas de minério de ferro, vem investindo, nesses últimos anos, em estudos de caracterização mineralógica de seus minérios explotados, como sustentação dos modelos geometalúrgicos de suas jazidas.

Neste trabalho, propóe-se fazer uma investigação de detalhe na microestrutura de minerais de ferro, mais especificamente em tipos de goethita presentes no material que 
alimenta o processo de flotação da Samarco. A relevância está no fato destes minerais serem muito comuns na jazida e apresentarem forte influência no comportamento dos minérios que os contém em abundância.

\section{2 - Tipologia dos minérios de Alegria}

As minas de minério de ferro da Samarco estão localizadas no Complexo de Alegria, no extremo leste do Quadrilátero Ferrífero, uma importante província mineral que está localizada no estado de Minas Gerais, Brasil (SAMARCO, 2004). Nelas, as encaixantes são filitos e quartzitos supracrustais pertencentes ao Grupo Caraça (inferior) e ao grupo Piracicaba Indiviso (superior) e, quanto ao minério, é representado principalmente por itabiritos da Formação Cauê do Grupo Itabira ${ }^{3}$.

As transformaçóes mineralógicas e texturais dos minérios de Alegria encontram-se fortemente vinculadas às condiçóes de temperatura e pressão que acompanharam os processos tectônicos que os afetaram e aos processos de origem intempérica e supergênica mais recentes, além, é claro, de variações intrínsecas às condições de deposição da formação ferrífera (ROCHA, 2008). Dessa forma, ao final da atuação desses processos, tem-se como resultado uma gama variada de tipos de itabirito e rochas associadas.

Os principais minerais de ferro dos itabiritos de Alegria são em ordem decrescente: 1) hematita, que ocorre principalmente sob a forma de martita (pseudomorfos octaédricos da magnetita, produto de sua oxidação) e em menor proporção, sob a forma lamelar ou especular; 2) goethita, que está presente principalmente sob as formas botrioidal, maciça, fibrosa (pseudomórfica de anfibólios) e terrosa e, 3) magnetita (euédrica a subédrica) que está normalmente em processo de martitização e apresenta-se em menor proporção que os demais. O quartzo é um dos principais minerais constituintes dos itabiritos e é o principal mineral da ganga. Além do quartzo podem ser encontrados, em pequena proporção, argilominerais (caulinita e gibbsita) e traços de micas. O quartzo encontra-se recristalizado, normalmente anédrico e associado aos minerais de ferro.

Esses itabiritos apresentam assembléias variadas em relação à predominância de um, dois ou mais dos minerais-minérios (hematita especular ou lamelar, martita, goethita e magnetita). Nos itabiritos anfibolíticos alterados, há a presença da goethita substituindo totalmente, de forma pseudomórfica, anfibólios fibrosos predecessores (grunerita e riebeckita) (ROCHA, 2008).

Para a elaboração da tipologia do minério, os itabiritos são subdivididos em diferentes tipos, baseados em suas associaçóes mineralógicas e em seu comportamento distinto em testes de bancada e em testes em escala piloto, que simulam todo o processo produtivo da Samarco (ROCHA et al., 2011). Atualmente estáo definidos os seguintes tipos

3 O Grupo Itabira constitui uma seqüência de metassedimentos de origem química subdivididos em duas formaçôes, da base para o topo: Cauê e Gandarela (DORR II, 1969). A Formação Cauê caracteriza-se por conter formaçóes ferríferas bandadas do tipo Lago Superior, representada por itabiritos siliciosos, itabiritos dolomíticos e itabiritos anfibolíticos (VERÍSSIMO, 1999). O ambiente deposicional dos sedimentos ferríferos originais pode ser considerado como tendo sido uma plataforma continental, onde a precipitação química se deu em grandes períodos transgressivos, ocorrendo deposição de sedimentos de fácies óxido, silicato e carbonato (SAMARCO, 2004). 
de itabiritos: especularítico (IE); martítico (IM); goethítico (IG); anfibolítico-martítico (IAM); anfibolítico goethítico (IAG); martítico especularítico (IME); especularítico goethítico (IEG); martítico goethítico (IMG) e martítico especularítico goethítico (IMEG).

Desta forma, o modelo geológico-tipológico elaborado a partir da associação dessas diversas tipologias de itabirito, carrega em si, além da informação mineralógica, também aquela referente ao comportamento destes itabiritos nos processos industriais.

\section{3 - Influência da goethita no processamento de minérios de ferro}

A goethita é um óxido de Fe hidratado e assim, sua cela unitária possui menos Fe que a da hematita e do que a da magnetita $(62,9 \%, 70 \%$, e $72,4 \%$, respectivamente). Por isso, a presença de uma maior quantidade de goethita significará um concentrado com menor conteúdo metálico $(\mathrm{Fe})$, quando comparado a concentrados ricos em hematita ou magnetita (FEITOSA et al., 1993). Além disso, esta hidratação, medida como a perda por calcinação (PPC), é também responsável por uma fragilização das características de resistência física de pelotas queimadas de minério de ferro, que é o produto final comercializado pela Samarco.

$\mathrm{Na}$ etapa de beneficiamento dos minérios de ferro, a goethita é um mineral gerador de lamas e um dos principais responsáveis pela perda de eficiência da filtragem, devido, principalmente, à sua característica de gerar, com maior facilidade, fraçóes ultrafinas em processos de cominuição. Por outro lado, mostra-se mais resistente à moagem nas suas formas maciça e botrioidal, levando ao aumento do consumo de energia, que é um dos insumos de maior custo para os processos de beneficiamento de minérios.

Quanto à influência das goethitas no consumo de reagentes no beneficiamento, observa-se uma correlação positiva delas tanto com o consumo de soda na etapa de deslamagem, como com o consumo de floculantes na etapa de espessamento. Já na flotação, o que se observa é que há uma tendência a aumentar-se o consumo de amido, que é o agente depressor de óxidos de ferro na flotação catiônica reversa de minérios itabiríticos, com o aumento dos percentuais de goethita, provavelmente devido à sua maior superfície específica (FEITOSA et al., 1993).

Outra característica das goethitas é a sua impureza química, que embora não afete o comportamento destes minerais em processos de beneficiamento ou aglomeração, influencia na qualidade dos produtos gerados a partir de materiais onde este mineral encontra-se em abundância. É sabido da literatura, que nos óxidos e oxihidróxidos de $\mathrm{Fe}, \mathrm{o} \mathrm{Fe}^{3+}$ na posição octaédrica pode ser parcialmente substituído por outros cátions metálicos trivalentes de tamanho similar, tais como $\mathrm{Al}^{3+}, \mathrm{Mn}^{3+}$ e $\mathrm{Cr}^{3+}$, sem modificação da estrutura (substituição isomórfica). Outros cátions, p. ex., Ni, Ti, Co, Cu e Zn podem também ser incorporados na estrutura dos óxidos/oxihidróxidos de ferro (SCHWERTMANN \& TAYLOR 1977). Também já é de conhecimento comum que a goethita apresenta quantidades variáveis de $\mathrm{SiO}_{2}$ e $\mathrm{Al}_{2} \mathrm{O}_{3}$ dentro de sua estrutura cristalina, bem como de outros elementos tais como o P, Ti, Mn, Cl, Mg e K (ROCHA, 1997). Assim, fica evidente a suposição de que elementos traços encontrados em amostras contendo goethita em abundância devam estar localizados, principalmente, na estrutura desses minerais. 


\section{4 - Mineralogia das amostras}

Foram coletadas duas amostras de $400 \mathrm{~kg}$ cada, da tipologia denominada como itabirito anfibolítico martítico, ambas alteradas, que afloram em regiōes diferentes de uma das minas de Alegria. As amostras foram preparadas para serem investigadas através de microscopia óptica e eletrônica de varredura (MEV).

A preparação constou de secagem em estufa, seguida de homogeneizações e quarteamentos, até que se obtivessem duas alíquotas correspondendo à quarta parte das amostras iniciais. Estas alíquotas foram então britadas em um britador de mandíbulas, de forma que todo o material ficasse com a granulometria inferior a $3,36 \mathrm{~mm}$. O produto desta britagem foi então homogeneizado e submetido a sucessivos quarteamentos, até que se conseguissem duas alíquotas de $1750 \mathrm{~g}$ cada. Estas alíquotas foram submetidas a três deslamagens sucessivas e após, cominuídas em moinho de bolas até que $90 \%$ do material moído estivesse com a granulometria inferior a $0,150 \mathrm{~mm}$, adequada ao processo de flotaçáo de itabiritos. O produto desta moagem gerou duas alíquotas de $50 \mathrm{~g}$ das quais foram elaboradas seçôes polidas para as análises de microscopia.

As seçôes polidas foram analisadas quantitativa (método de contagem de grãos) e qualitativamente com o auxílio de um microscópio óptico de luz refletida e transmitida, marca Leitz/Leica, modelo Laborlux 12POL S. Para a investigação mais detalhada da microestrutura dos minerais, as seçôes polidas foram devidamente preparadas e analisadas no MEV utilizando-se um microscópio da marca Jeol JSM-5410, com um espectrómetro de energia dispersiva de raios-X (EDS) acoplado da marca Noran e modelo TN-M3055. Adicionalmente, com o objetivo de aumentar o limite de resolução e proporcionar uma investigação de maior detalhe das microestruturas das goethitas, as seçóes foram levadas a análises no microscópio eletrônico de varredura com canhão de emissão por efeito de campo (field efect gun - FEG), da marca FEI, modelos Quanta 200 FEG (resolução 1,6 $\mathrm{nm}$ a $30 \mathrm{kV}$ em alto vácuo) e Dual-FIB Quanta 3D (resolução-feixe de elétrons de 0,8 nm a $30 \mathrm{kV}$ em alto vácuo).

A tabela 1 apresenta os resultados das análises mineralógicas quantitativas das amostras.

Tabela 1 - Resultados das análises mineralógicas quantitativas.

\begin{tabular}{|c|c|c|c|c|c|c|c|c|c|c|c|c|}
\hline \multicolumn{13}{|c|}{ Mineralogia dos Itabiritos anfibolíticos martíticos alterados } \\
\hline \multirow{2}{*}{ Amostras } & \multicolumn{2}{|c|}{$\mathrm{He}(\%)$ * } & \multicolumn{2}{|c|}{$\mathrm{Hm}(\%)$ ** } & \multicolumn{2}{|c|}{$\mathbf{G}(\%) * * *$} & \multicolumn{2}{|c|}{$\mathbf{M}(\%)^{* * * *}$} & \multicolumn{2}{|c|}{$\mathbf{Q}(\%) * * \star * *$} & \multicolumn{2}{|c|}{$\mathrm{C}$ e Gb $(\%) * * \star * \star * *$} \\
\hline & Vol & Peso & Vol & Peso & Vol & Peso & Vol & Peso & Vol & Peso & Vol & Peso \\
\hline$A 61$ & 0 & 0 & 26 & 35 & 28 & 30 & 7 & 9 & 40 & 27 & - & - \\
\hline$A 62$ & 1 & 1 & 15 & 21 & 43 & 48 & 3 & 4 & 38 & 26 & - & - \\
\hline
\end{tabular}

${ }^{*} \mathrm{He}$ - hematita especular; ${ }^{* *} \mathrm{Hm}$ - hematita martítica (martita); *** G - goethita; ${ }^{* * * *} \mathrm{M}-$ magnetita; ${ }^{* * * * *} \mathrm{Q}-$ quartzo; ${ }^{* * * * * *} \mathrm{C}$ e $\mathrm{Gb}$ - caulinita e gibbsita, respectivamente.

A martita $(\mathrm{Hm})$, a goethita $(\mathrm{G})$ e o quartzo $(\mathrm{Q})$ são os principais minerais e a magnetita (M) encontra-se em baixa proporção. A hematita especular (He), bem como os argilominerais, não estão presentes. 


\section{1 - Amostra A61 - Características dos minerais e microestruturas}

De forma geral, os minerais têm tamanho variado (dimensóes micrométricas até milimétricas) e porosidade em grau médio.

314 As goethitas estão presentes sob as formas botrioidal e intra grão de martitas, sendo neste último caso, também geradas a partir da alteração pseudomórfica da magnetita anterior. A goethita terrosa encontra-se em baixa proporção e pseudomorfos de anfibólio são raros. Já as martitas são em sua maioria subédricas e apresentam variados graus de alteração, sendo aquelas mediamente alteradas e porosas as mais abundantes. A magnetita está normalmente presente como relíquias dentro das partículas de martita (goethitizadas ou não) e o quartzo é anédrico, podendo estar liberado (maioria) ou associado aos demais minerais de ferro.

A Fig. 1 mostra a goethita botrioidal típica, magnetitas totalmente martitizadas e goethitizadas e o quartzo. Já na Fig. 2, observa-se a goethita maciça associada a magnetitas pouco martitizadas, além de partículas de martita e quartzo. As imagens foram obtidas no microscópio óptico (MO) em luz refletida com os nicóis paralelos (LRNP).

A Fig. 3, que é uma fotomicrografia tirada ao MEV com imagem de elétrons retroespalhados (IRE), mostra duas martitas também goethitizadas, muito porosas, associadas a goethita botrioidal. Nas martitas observam-se, tanto a textura típica de treliça, gerada a partir da formação da hematita nos planos ou entre os planos de partição octaédricos da magnetita, como também a textura esqueletal, que é uma das feiçóes texturais mais comuns em minérios de ferro e é gerada a partir da lixiviação preferencial da goethita quando em presença continuada de água (MORRIS, 1980). As regióes marcadas na goethita botrioidal foram também analisadas pelo microanalisador EDS. Os resultados encontrados (Tabela 2) são típicos das goethitas de Alegria, que sempre apresentam como impureza principal a sílica, ora também a alumina e menos frequentemente o fósforo. Outros elementos como o Ti, Mn, Mg também podem estar presentes.

A Fig. 4 mostra a imagem de elétrons secundários (IES) tirada no MEV-FEG FIB onde se pode observar a textura de duas regióes de uma mesma goethita maciça, separadas por uma descontinuidade (fratura). A porção inferior apresenta um aspecto mais liso que a superior e mesmo no maior aumento (> 30 000x), não são observados nem microporos nem a presença de outra fase mineral associada.

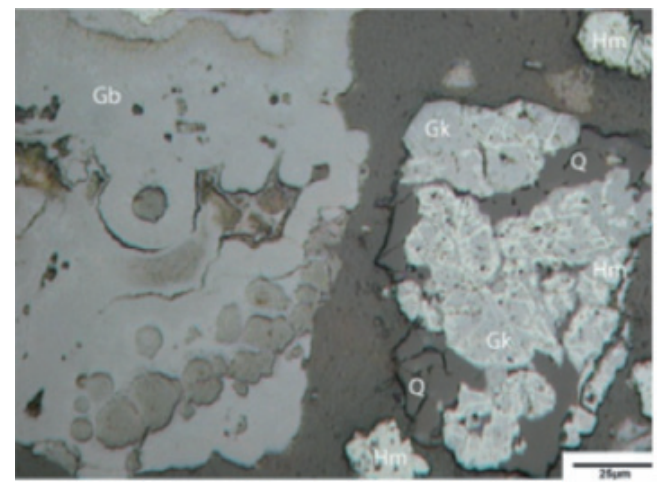

Fig. 1 - Fotomicrografia mostrando goethita botrioidal (Gb), martitas (Hm), goethitas produto da alteração da magnetita (Gk) e quartzo (Q) 


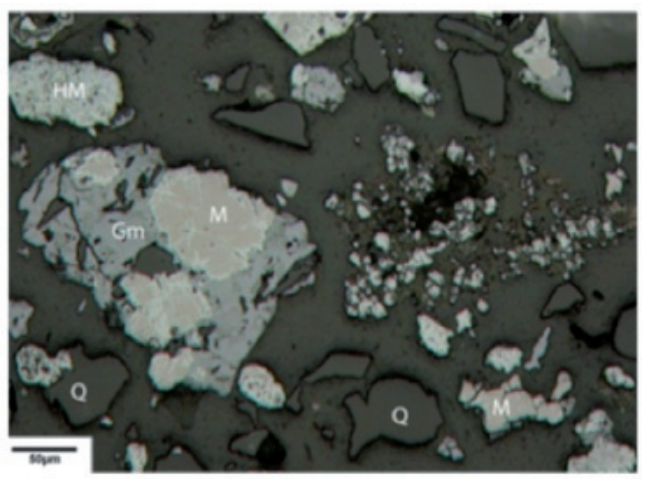

Fig. 2 - Fotomicrografia mostrando goethita maciça $(\mathrm{Gm})$, martita (HM), magnetita (M) e quartzo (Q).

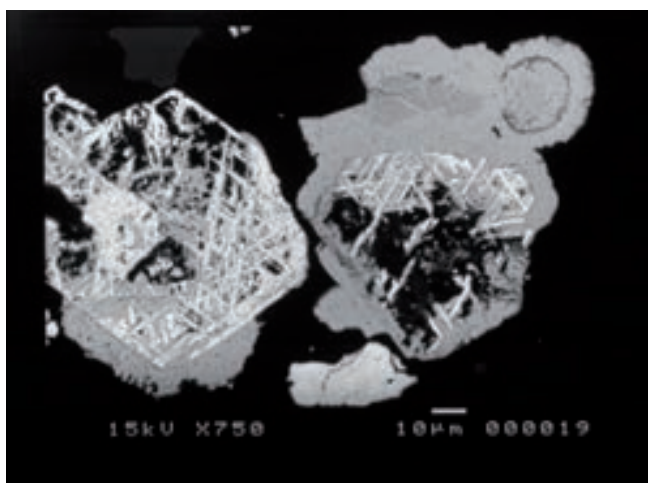

Fig. 3 - Imagem (MEV-IRE) mostrando martitas e goethitas. As regióes marcadas (1 a 4) foram analisadas pelo EDS.

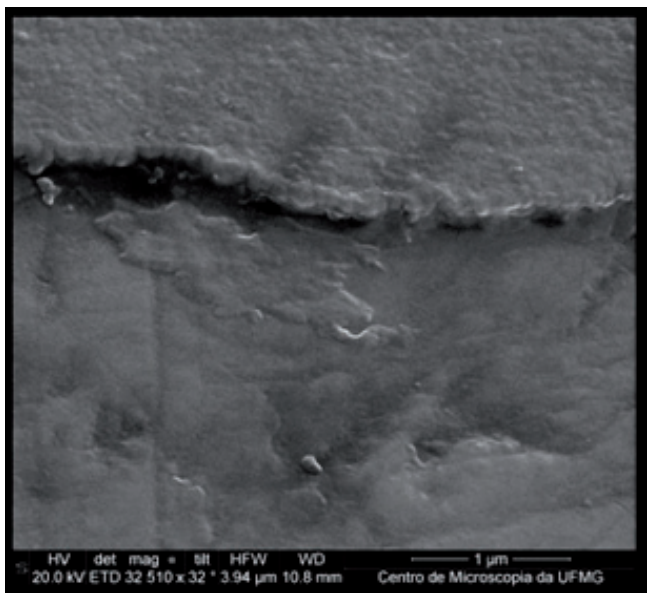

Fig. 4 - Imagem (MEV-FEG) de goethita maciça. 


\begin{tabular}{|c|c|c|c|c|}
\hline \multirow{2}{*}{ Área } & \multirow{2}{*}{ Mineral } & \multicolumn{3}{|c|}{ Elementos químicos (\%) } \\
\hline & & $\mathrm{Fe}$ & $\mathrm{SiO}_{2}$ & $\mathrm{Al}_{2} \mathrm{O}_{3}$ \\
\hline 1 & Goethita & 60,04 & 3,79 & 0,91 \\
\hline 2 & Goethita & 58,14 & 4,10 & 3,62 \\
\hline 3 & Goethita & 57,75 & 4,45 & 3,88 \\
\hline 4 & Goethita & 58,75 & 1,71 & 2,00 \\
\hline
\end{tabular}

\section{2 - Amostra A62 - Características dos minerais e microestruturas}

Para essa amostra, tanto o nível de alteração dos minerais de ferro como a porosidade dos mesmos são de grau elevado. O tamanho das partículas é variado.

A goethita ocorre principalmente nas formas botrioidal, pseudomórfica de anfibólio e terrosa. A martita está muito alterada e porosa, sendo frequente a observação da textura esqueletal associada a goethita terrosa. A magnetita é reliquiar nas martitas e o quartzo é anédrico e pode ser encontrado localmente substituindo anfibólio anterior (pseudomórfico), como ocorre com as goethitas.

Nas Figs. 5 e 6 são apresentadas as imagens observadas no microscópio óptico de goethitas pseudomórficas de anfibólios e botrioidal, além de martitas com diferentes porosidades. Estas são as formas típicas de ocorrência destes minerais nos minérios anfibolíticos de Alegria.

A sequência de imagens de elétrons retroespalhados tiradas no MEV-FEG (Figs. 7 a 9) mostra a textura fibrosa da goethita pseudomórfica de anfibólio. Como pode ser visto, a fibrosidade do anfibólio é claramente observada na goethita sob todas as ampliaçóes. Outra observação pertinente é a de que mesmo na maior ampliação (Fig. 9), somente se observa a goethita fibrosa pseudomórfica como a única fase mineral presente.

A Fig. 10, uma imagem de elétrons secundários (MEV-FEG), mostra em detalhe a textura de treliça da martita, onde pode ser observada a substituição da hematita nos planos da magnetita.

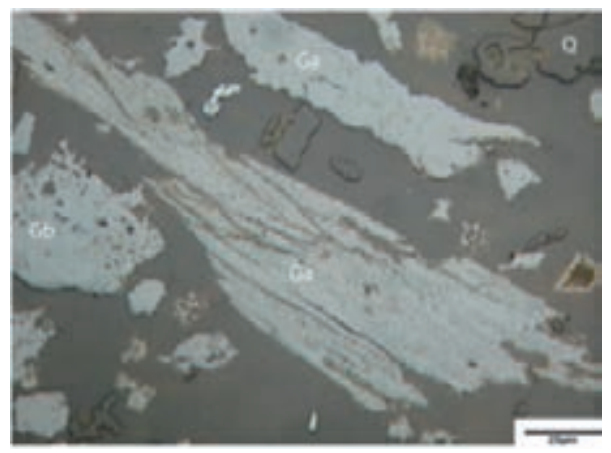

Fig. 5 - Fotomicrografia mostrando goethitas botrioidal (Gb) e pseudomórfica de anfibólio (Ga) e quartzo (Q). 


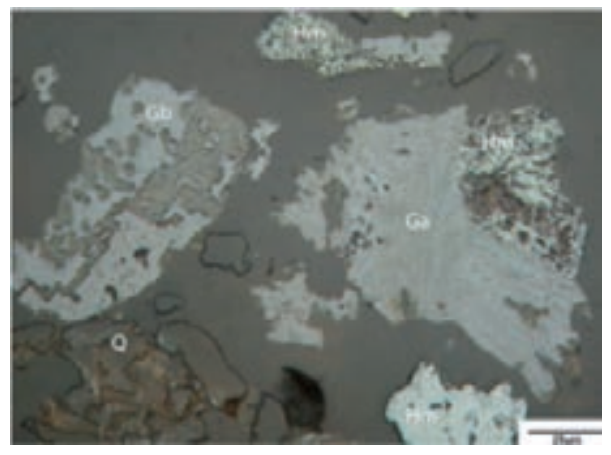

Fig. 6 - Fotomicrografia mostrando goethitas botrioidal (Gb e Ga), martitas (Hm) e quartzo (Q).

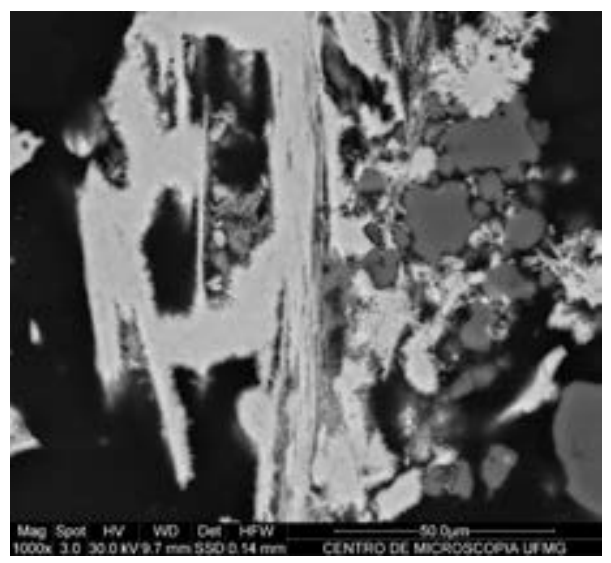

Fig. 7 - Imagem (MEV-FEG) de goethita pseudomórfica de anfibólio.

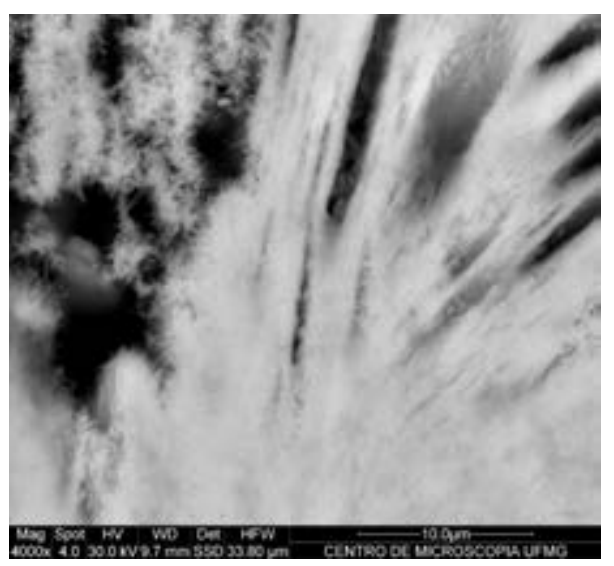

Fig. 8 - Ampliaçáa em uma porção da goethita da Fig. 7. 


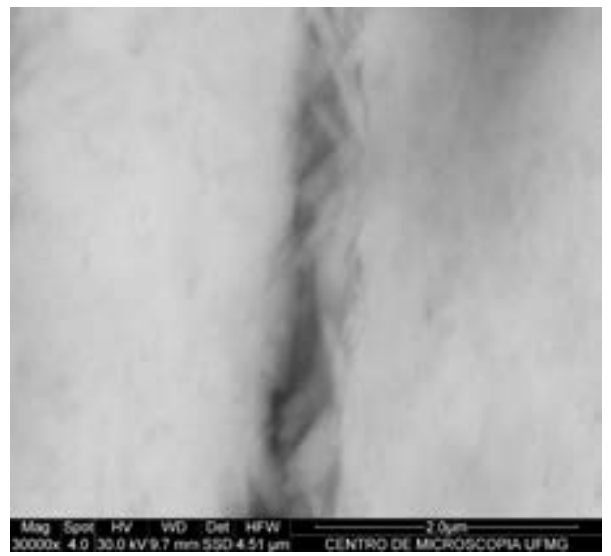

Fig. 9 - Maior ampliação na região da Fig. 8.

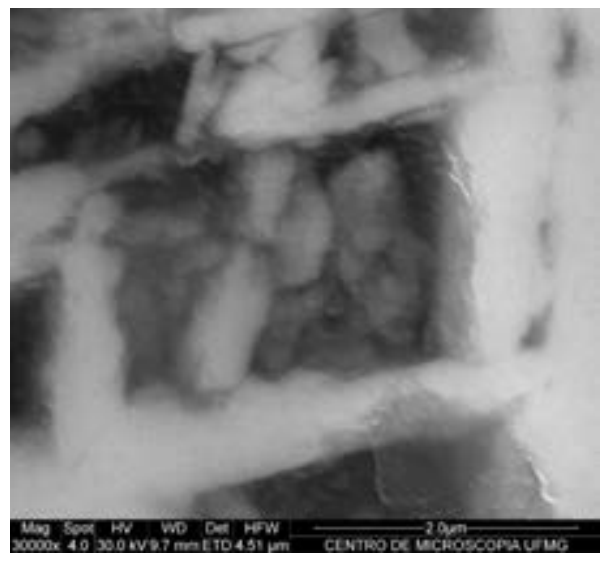

Fig. 10 - Imagem (MEV-FEG) de detalhe na textura de treliça da martita.

\section{5 - Consideraçóes finais}

As amostras de itabirito investigadas apresentam como principais fases mineralógicas de ferro a martita, que pode conter relíquias de magnetita ou goethita associada (goethitização da magnetita) e a goethita, sendo esta última presente, principalmente, sob as formas botrioidal, terrosa-maciça e pseudomórfica de anfibólio. O grau de porosidade desses minerais varia de médio a alto, o que, aliado à própria mineralogia está totalmente coerente com o ambiente e processo de geraçáo desses minérios, que foi por enriquecimento supergênico.

As feiçóes texturais da martita, treliça e esqueletal, observadas nestas amostras, são típicas desse mineral nos minérios de Alegria. A hematita lamelar, de textura lisa e 
pouca porosidade, é totalmente distinta da martita tanto na forma, textura e porosidade como no comportamento frente a processos de beneficiamento, tais como a cominuiçáo e a flotação.

A goethita, quando em sua forma maciça, é totalmente distinta de quando está botrioidal ou substituindo de forma pseudomórfica o anfibólio. Essas diferenças, que são nítidas e observáveis tanto a olho nu, como ao microscópio óptico e permanecem em aumentos de grande amplitude, também se refletem em um comportamento diferenciado desse mineral em processos de beneficiamento.

\section{Referências Bibliográficas}

DORR II, J. V. N. (1969) - Physiographic, Stratigraphic, and Structural Development of the Quadrilátero Ferrífero. Minas Gerais, Brazil. U. S.Geol. Surv. Prof. Pap., Washington, 641-A, p. A1-A103.

FEITOSA, V. M. N., SILVA, J. P., RABELO, P. J. B. \& COELHO, L. H. (1993) - Estudos de caracterização mineralógica e suas implicaçôes no processo na mina de Alegria. In: Simpósio de Geologia de Minas Gerais, 7o, 1993, Belo Horizonte. Anais do workshop de geologia estrutural dos minérios de ferro. Belo Horizonte: FAPEMIG, 1993, p. 369-373.

MORRIS, R. C. (1980) - A textural and mineralogical study of the relationship of iron ore to banded ironformation in the Hamersley Iron Province of western Australia. Economic Geology. 75, p. 184-209.

ROCHA, J. M. P. (1997) - Caracterização de Minérios Goethíticos-limoníticos da Mina de Alegria, MG. Belo Horizonte: Escola de Engenharia da UFMG, 257 p. Dissertação de Mestrado apresentada ao Curso de Pós-Graduação em Engenharia Metalúrgica e de Minas da Universidade Federal de Minas Gerais.

ROCHA, J. M. P. (2008) - Definição da Tipologia e Caracterização Mineralógica e Microestrutural dos Itabiritos Anfibolíticos das Minas de Alegria da Samarco Mineraçấo S.A. - Minas Gerais. Belo Horizonte: Escola de Engenharia da UFMG. 2vol. Tese de Doutorado apresentada ao Curso de Pós-Graduação em Engenharia Metalúrgica e de Minas da Universidade Federal de Minas Gerais, 460 p.

ROCHA, J. M. P., BRANDÁO, P. R. G. \& CANÇADO, R. Z. L. (2011) - Characterisation of the amphibolitic itabirites of the Alegria Mines, Minas Gerais, Brazil. Proceedings, Geomin 2011 - 2nd. International Seminar on Geology for the Mining Industry, Antofagasta, Chile, 08-10 June, Gecamin, Santiago, p. 1-10.

SAMARCO MINERAÇÃO S. A. (2004) - Projeto Terceira Planta de Pelotização; Estudo de Pré-viabilidade. Mariana (Relatório Interno), 465 p.

SCHWERTMANN, U. \& TAYLOR, R. M. (1977) - Iron Oxides. In: Dixon, J. B. (eds.). Minerals in soil environments, Wiscosin, p. 145-180.

VAN VLACK, L. H. (1984) - Princípios de Ciências e Tecnologia dos Materiais. Rio de Janeiro: Editora Campus, $567 \mathrm{p}$

VERÍSSIMO, C. U. V. (1999) - Jazida de Alegria: Gênese e Tipologia dos Minérios de Ferro; Minas 3,4 e 5 - Porção Ocidental. Rio Claro: Instituto de Geociências e Ciências Exatas da Universidade Estadual Paulista, 2vol. Tese de Doutorado elaborada junto ao Curso de Pós-Graduação em Geociências - Área de Concentração em Geologia Regional, 234 p.

VIEIRA, C. B., ARAÚJO, F. G. S., ROSIÈRE, C. A., SESHADRI, V. \& COELHO, L. H. (2009) - Geometallurgical Approach for Quality Control of Iron Ores for Agglomeration and Reduction Processes. In: $17^{\text {th }}$ Steelmaking Conference $-7^{\text {th }}$ Ironmaking Conference $-1^{\text {st }}$ Cleaner Production Seminar (IAS-JICA), Rosário, Argentina. 14 p. 